\title{
Instrucciones para los autores
}

Animal Genetic Resources/Resources génétiques animales/ Recursos genéticos animales es una revista trilingüe, publicada tres veces al año electrónicamente en internet (http://journals. cambridge.org/AGR) y de forma impresa. Los principales trabajos son publicados en inglés, francés y español, con resúmenes en estos tres idiomas. La revista viene siendo publicada desde el año 1983 y todas las ediciones pasadas están disponibles en el enlace: http://dad.fao.org/cgi-bin/EfabisWeb.cgi?sid=-1,refcat_ 50000044

La revista invita a la presentación de trabajos desde cualquier parte del mundo. Aquellos autores que no posean un nivel elevado en alguno de las tres lenguas aceptadas, les solicitamos que busquen la ayuda necesaria en este sentido antes de remitirnos sus manuscritos.

\section{Misión}

La revista proporciona un foro internacional para la publicación de trabajos relacionados con la gestión de los recursos genéticos animales para la alimentación y la agricultura (AnGR). En concreto, se tratan las siguientes áreas: caracterización fenotípica y molecular; sondeo y seguimiento; desarrollo (mejora genética); utilización sostenible; desarrollo de las capacidades de los ganaderos y las comunidades de pastores; y políticas e instituciones.

Los editores aceptan todos los trabajos enviados que traten sobre los temas mencionados anteriormente. Trabajos relativos a razas y tecnologías que contribuyan a la gestión sostenible de los sistemas de producción con ingresos medios y bajos en el mundo, que comprenden la mayor parte de las tierras dedicadas a la producción ganadera y la mayor parte de la producción del ganado, que son los que ostentan mayor grado de interés.

La revista apoya la implementación del Plan de Acción Mundial sobre los Recursos Zoogenéticos, el marco de trabajo acordado para la gestión de los AnGR y el Convenio sobre la Biodiversidad.

\section{Descargo de responsabilidad}

Los puntos de vista expresados en los trabajos publicados en Animal Genetic Resources/Resources génétiques animales/ Recursos genéticos animales son solamente las opiniones del autor o autores y, por tanto, no reflejan necesariamente las políticas de la FAO o los puntos de vista de los editores o de las instituciones a las que dichos autores pertenecen.

\section{Evaluación de expertos}

Los manuscritos enviados para su publicación en Animal Genetic Resources/Resources génétiques animales/Recursos genéticos animales serán estudiados minuciosamente por parte de dos críticos externos. Lo ideal es que los manuscritos sean evaluados por los críticos externos y por los editores, recayendo la decisión final acerca de los mismos sobre los editores.

\section{Categorías de los trabajos}

Trabajos sobre investigación - Se tomarán en consideración para su publicación en Recursos genéticos animales los trabajos relacionados con la gestión de los AnGR. Se invita a los autores a incluir las fotografías de alta calidad pertinentes relativas al trabajo presentado en sus manuscritos. Si las fotografias ilustran animales, éstas deben mostrar el entorno de producción primario al que estos animales se han adaptado.

Trabajos de revisión - Se podrán tomar en consideración ocasionalmente aquellos trabajos que presenten una revisión del desarrollo a nivel de nacional, regional o mundial en uno o más aspectos de la gestión de los AnGR. Estos trabajos podrán incluir las revisiones del estado actual de campos específicos de la gestión de los AnGR.

Artículos específicos - Los artículos relacionados con los temas de la revista serán publicados cuando los editores lo consideren oportuno.

Otros trabajos publicados: Se invita a los lectores a enviar la siguiente información a la dirección de correo electrónico: AnGR-Journal@fao.org

- Revisiones o propuestas de libros.

- Conclusiones y recomendaciones resultantes de reuniones, talleres y conferencias relevantes.

- Anuncios de cursos de capacitación y eventos a nivel nacional, regional o internacional.

\section{Originalidad y copyright}

Para poder ser publicado en la revista Recursos genéticos animales, el manuscrito deberá no haber sido publicado previamente o estar bajo estudio para ser publicado. (Los datos que hayan sido publicados previamente podrán ser usados en la revista con precaución y siempre y cuando se obtenga el permiso necesario). Antes de la publicación, el autor del manuscrito deberá firmar y entregar, en su nombre y en el de los co-autores, una autorización y un formulario de consentimiento de transferencia a la editorial. Este formulario se enviará al autor junto con la prueba del artículo a publicar.

\section{Autoría}

Los artículos que tengan múltiples autores serán revisados bajo el supuesto de que todos los autores han contribuido a la investigación descrita en el artículo y aprueban tanto el artículo en su totalidad como el envío y la publicación de éste. Contribución al trabajo presentado supone la concepción y el diseño del proyecto, los resultados de los experimentos y/ o el análisis e interpretación de los datos. Los autores deberán haber contribuido sustancialmente al borrador o a la revisión de dicho trabajo. 


\section{Presentación del Manuscrito}

Todos los manuscritos deberán enviarse online, y sin coste alguno para el autor, a través de la página Web: http:/ journals.cambridge.org/AGR.

Posteriormente al envío del manuscrito, se mandará acuse de recibo junto con un número de referencia y el manuscrito será presentado para ser estudiado. Para toda correspondencia relacionada con el manuscrito, se deberá incluir el número de referencia mencionado.

Se deberán seguir las siguientes instrucciones (para más información, ir a la sección "Preparación y estilo de manuscrito"):

- Los manuscritos se presentarán en ingles, francés o español. Si el manuscrito está escrito en francés o español se deberá incluir un resumen, así como palabras clave en el mismo idioma además del inglés. Todos los artículos publicados presentarán un resumen en inglés, francés y español. Se agradecerá el envío del resumen en los tres idiomas con objeto de reducir gastos de traducción y acelerar el proceso del manuscrito.

- El formato deseado de documento para la presentación es Microsoft Word. No se aceptarán manuscritos enviados en Word Perfect u otros procesadores de texto. Los cuadros se incluirán al final del documento, siguiendo el orden indicado por los marcadores de posición dentro del texto.

- Las figuras deberán presentarse en documentos separados con una resolución apropiada (Para más información ver "Preparación y estilo de manuscrito").

- Se deberá presentar una carta de presentación en un documento por separado. La carta deberá indicar la categoría bajo la que el manuscrito se presenta (Ver apéndice 1) y los datos del autor (número de teléfono, fax, y dirección de correo electrónico).

- Los nombres de los archivos enviados deberán indicar el nombre completo o abreviado del autor principal.

- No se requiere ni deberá enviarse copia en papel del manuscrito, de los cuadros o de las figuras.

Tenga en cuenta que toda correspondencia en relación con los manuscritos presentados y analizados se hará exclusivamente con el autor principal.

\section{Preparación y estilo del manuscrito}

El formato del manuscrito deberá tener un espaciamiento doble entre líneas. Las páginas deberán estar numeradas, siendo la página número uno la que lleva el título del artículo. Los márgenes de las páginas deberán tener al menos $2.5 \mathrm{~cm}$. en todas sus caras. La letra debe ser estilo "Arial".

Autores y afiliaciones - Los nombres y afiliaciones de los autores deberán presentarse en el formato siguiente:

E.C. Quispe ${ }^{1}$, T.C. Rodríguez ${ }^{2}$, L.R. Iñiguez ${ }^{3}$ and J.P. Mueller ${ }^{4}$

${ }^{1}$ Universidad Nacional de Huancavelica, Huancavelica, Perú; ${ }^{2}$ Universidad Mayor de San Andrés, La Paz, Bolivia; ${ }^{3}$ Cochabamba, Bolivia; ${ }^{4}$ Instituto Nacional de Tecnología Agropecuaria, Bariloche, Argentina.

Correspondencia: E.C. Quispe, Universidad Nacional de Huancavelica, Huancavelica, Perú. E-mail: edgarquispe62 (a)yahoo.com
El título abreviado tendrá un máximo de 50 caracteres y aparecerá en la página 1 del manuscrito.

El resumen no deberá tener estructura o subtítulos y deberá proporcionar al lector una sinopsis que sea independiente del documento. Deberá incluir una breve introducción, la metodología usada, los resultados obtenidos y las conclusiones. El resumen no deberá exceder de 210 palabras en inglés y 250 palabras en francés y español. El resumen deberá ser seguido de tres a cinco palabras clave separadas por una coma. Tanto el resumen como las palabras clave se escribirán en el mismo idioma del manuscrito además del inglés.

El texto principal del manuscrito deberá empezar en la página número 3 y las referencias deberán comenzar en una página nueva. Las líneas de texto deberán estar numeradas y el manuscrito estructurado con encabezamientos numerados consecutivamente (eje. 1., 1.1, 1.1.1 etc.). Es importante evitar el uso de referencias cruzadas cuando se use la numeración de los encabezamientos, en cuyo caso la editorial eliminará la numeración y aplicará los estilos de encabezamiento en la versión final.

Adicionalmente, los trabajos de investigación deben incluir los siguientes encabezamientos: Materiales y métodos, Resultados, Discusión y Conclusiones.

La extensión máxima del texto principal del manuscrito no deberá exceder de 10 páginas (8.500 palabras aprox.). En caso de que el texto sea corto, éste no deberá exceder de una página (750 palabras ó 500 palabras si se incluye una imagen).

Los Cuadros deberán ser numerados consecutivamente tal y como están citados en el texto (Cuadro 1, 2 etc.). Cada cuadro deberá aparecer en una página distinta (al final del documento) con la numeración y título arriba y las anotaciones o comentarios debajo del mismo.

Las figuras se numerarán consecutivamente tal y como están citadas en el texto del documento (Figura 1, 2, etc.). Se deberán usar caracteres en cursiva para apartados a, b, c, etc. Cada figura deberá incluir una leyenda. En caso que corresponda, las figuras se deberán enviar en archivos con formato TIFF o EPS, preferiblemente con el mismo tamaño con el que serán reproducidos o publicados. Las ilustraciones o material gráfico deberán enviarse en blanco y negro con una resolución de 1200 dpi; las combinaciones de material gráfico con una resolución de $800 \mathrm{dpi}$; el material gráfico en modelo de semitono en blanco y negro deberá guardarse bajo el modo "escala de grises" con una resolución de 300 dpi; el material gráfico en modelo de semitono a color se guardará bajo modo "CMYK" con una resolución de 400 dpi. Se deberán obtener todos los permisos necesarios.

Abreviaturas y el sistema internacional de unidades (SI) - No se recomienda el uso de abreviaturas excepto aquellas extensamente utilizadas. Las abreviaturas deberán usarse sólo en caso de que mejoren la comprensión del manuscrito. Los acrónimos deberán ser escritos en palabras completas la primera vez que se mencionen. Se usarán las medidas del sistema métrico internacional (SI).

\section{Lista de agradecimientos}

En esta sección el autor deberá hacer mención a la ayuda económica recibida, por parte de las agencias de financiación u otras fuentes, 
para la realización del trabajo documentado en el manuscrito. También se podrán incluir, en esta sección, los agradecimientos a las personas que contribuyeron a la investigación pero que no aparecen como autores.

La lista de agradecimientos deberá aparecer después del texto principal antes de las referencias. En caso de que no haya agradecimientos, la palabra "ninguno" seguirá al encabezamiento "Lista de agradecimientos".

\section{Declaración de interés}

Existe conflicto de intereses cuando un autor tiene intereses que pudieran influir de forma inapropiada en su opinión o juicio, incluso si su opinión no ha sido finalmente influenciada. Por esta razón, los autores deberán revelar conflictos de intereses potenciales de forma que se pueda evaluar sobre sus efectos. En el momento en que se envíe el manuscrito, los autores deberán revelar cualquier acuerdo o conexiones económicas que puedan tener, que sean pertinentes al manuscrito enviado y que puedan ser percibidas como potencial amenaza a la imparcialidad del documento. También deberán declararse los intereses no-financieros que pudieran ser relevantes en este contexto. En caso de que no haya intereses relevantes, deberá también indicarse. Este requerimiento será aplicable a todos autores del documento y a todas las categorías de documentos.

\section{Referencias}

Toda referencia presente en el texto deberá aparecer en la lista de referencias y, de la misma manera, cada referencia de la lista deberá haber sido citada por lo menos una vez en el texto. Las referencias deben ir en orden alfabético del apellido del autor, seguido por el año.

Ejemplos:

1. Ejemplo en el caso de una referencia de una revista: Köhler-Rollefson, I. 1992. The camel breeds of India in social and historical perspective. Animal Genetic Resources Information 10: 53-64.

2. Cuando se trate de más de un autor:

Matos, C.A.P., Thomas, D.L., Gianola, D., Tempelman, R. J. \& Young, L.D. 1997. Genetic analysis of discrete reproductive traits in sheep using linear and non-linear models: 1. Estimation of genetic parameters, Journal of Animal Science 75: 76-87.

3. En el caso de un libro o de una publicación ad hoc, por ejemplo informes, tesis, etc.

FAO, 2007. Global Plan of Action for Animal Genetic Resources and the Interlaken Declaration. Food and Agriculture Organization of the United Nations, Rome, Italy (available at http://www.fao.org/docrep/010/a1404e/ a1404e00.htm)

Van der Werf, J., Graser, H-U., Frankham, R. \& Gondro, C. (eds.) 2009. Adaptation and fitness in animal populations. evolutionary and breeding perspectives on genetic resources management. Springer.

4. Cuando se trate de un artículo dentro de las actas de una reunión:
Abad, M., Arrigo, J., Gibbons, A., Lanari, M.R., Morris, G. \& Taddeo, H. 2002. Breeding scheme for Angora goat production in North Patagonia. Proceedings 7th World Congress on Genetics Applied to Livestock Production, 19-23 August 2002, Montpellier, France, 12-14.

5. Cuando la información contenida en el artículo haya sido obtenida o derive de un sitio Web:

FAO. 2010. Domestic Animal Diversity Information System, http://www.fao.org/dad-is/, Food and Agriculture Organization of the United Nations, Rome, Italy.

En caso de trabajos que hayan sido aceptados para publicación pero que no hayan sido todavía publicados, se deberá escribir "en prensa" en lugar del año de publicación. No deberá indicarse el año estimado de publicación.

\section{Material suplementario online}

La plataforma online ofrece a los autores la oportunidad de incluir datos que serían imposibles o impracticables de incluir en la versión impresa de la revista. Los autores podrán incluir cuadros y figuras, así como videos, imágenes 3-D, grandes bases de datos o cualquier material adicional que no se pueda imprimir. Todo material suplementario deberá ser enviado con el manuscrito original. Los datos suplementarios deberán referirse en el texto del documento con el prefijo "S" (ej. Cuadro suplementario S1, Figura suplementaria S1). Los archivos suplementarios o adicionales no serán editados ni corregidos, y serán publicados tal y como se envíen. La publicación electrónica del material suplementario necesitará ser aprobada por los editores. Por otra parte, el manuscrito deberá ser autónomo sin el material suplementario (en beneficio de los lectores que sólo tengan acceso a la copia impresa).

\section{El proceso de revisión}

Los manuscritos enviados a la revista serán estudiados por dos críticos externos y evaluados por uno de los editores. Si los editores consideran que un documento no es relevante para la revista o que tiene pocas posibilidades de tener una buena evaluación, podrá ser devuelto al autor después de la primera revisión por parte de los editores. Este proceso de rechazo rápido facilita al autor enviar su trabajo para publicación a otros medios. Los manuscritos también podrán ser rechazados por los editores si no se ajustan a las recomendaciones de preparación de manuscritos. Se hará todo lo posible por informar a los autores sobre la revisión dentro del plazo de seis semanas tras la recepción del manuscrito. $\mathrm{Si}$ los editores requieren revisiones de un manuscrito antes de su publicación, se dará un máximo de un mes para que dicha revisión se haga efectiva.

\section{Pruebas}

La editorial se reserva el derecho a corregir manuscritos con objeto de asegurar que la gramática y la ortografía van en consonancia con el estilo de la revista. El autor recibirá pruebas de página para su última corrección. Las pruebas de página deberán ser revisadas y restituidas por el autor dentro de dos días después de su recepción. La editorial se reserva el derecho de cobrar una cantidad a los autores en caso de excesiva corrección de errores no tipográficos. 